\title{
Research on the Impact of Intelligent Decision- Making System for Voluntary Filling in College Entrance Examination on Senior High School Students
}

\author{
Yinghui Wang, Yizhen Liu*, Li Liu \\ School of Sugon BigData Liaoning Institute of Science and Technology \\ Benxi Liaoning China \\ 15998203039@163.com
}

\begin{abstract}
College Entrance Examination is one of the keys to change the fate of our own life. So it would become very important for senior three students to fill in voluntarily. Most of the candidates are difficult to choose their own specialties and colleges according to their own characteristics, and the adjustment of students' state in the preparation process is also one very important part. Based on the above problems, we have developed an intelligent decision-making system for college entrance examination voluntary filling, which provides real-time and scientific reasonable filling suggestions for senior three students, and solves the problem of senior three students filling in voluntary filling in combination with their own characteristics and interests. This letter describes in detail the research and analysis of the impact of the intelligent filling system on senior high school students, and makes an effort for the country to select talents with high-level professional knowledge and achieve "two hundred-year goals" for China. To finish this task, our team user big data technology including data mining, data visualization and the like.
\end{abstract}

Keywords-High School Students; Intelligent Decision-making System for Voluntary Filling in College Entrance Examination; Research and Analysis of the Impact on High School Students

\section{INTRODUCTION}

For senior students, College Entrance Examination undoubtedly becomes an opportunity to change their destiny, instead, students spent most of their time in reviewing cultural lessons, they do not know much about the research contents of various professional fields, which specialties they are suitable for, and the comprehensive ranking of colleges and universities in this regard, and they do not know that the level about themselves and the schools they want to apply is still much lower far away. Therefore, in order to have a better choice, the college entrance examination voluntary filling in has become a crucial part. So who will give the students a well-founded suggestion? Big data is not only a technology, but also an idea of solving problems. I led the team members to design our intelligent decision-making system of voluntary filling in order to solve the above problems.

According to statistics [1], the total number of the national college entrance examination in 2018 is 9.75 million, which is an increase of 350,000 compared with 2017, which is the largest number of applicants since 2010.To cite two distinct examples, Shandong Province, as the representative of the big province of college entrance examination, has nearly 600,000 applicants in 2018, and Liaoning Province has 185,000 applicants in 2018. In order to make the competition between the students in the university entrance examination provinces less fierce and to stop the outflow of talent, we have studied an intelligent decision-making and voluntary filling of college entrance examination, hoping to alleviate this series of problems to a certain extent.

The intelligent decision-making system for College Entrance Examination voluntary filling-in includes six modules Finding College information, Professional details, VIP service, Admission batches, Efficient prediction, Voluntary filling-in. It provides a reference guidance and suggestion to our registered users precisely and directionally, so that they will no longer feel helpless and tangled when facing voluntary filling-in. This system breaks through the traditional complicated determination of data, it can reasonably predict by inputting the corresponding screening conditions, thus solving the above pain points, and has a better application and practical practice of our professional knowledge.

II. Home Page Design of InTELligent DeCiSIONMAKING SYSTEM FOR COLLEGE ENTRANCE EXAMINATION VOLUNTEER FILLING

Our team's main design idea is concise and "bright". One is for users to have a strong experience. The other is for senior three students to review or tense anxious waiting results in order to relax their body and mind. The home page is shown in Fig. 1 below. And some of other page is shown in Fig.2. 


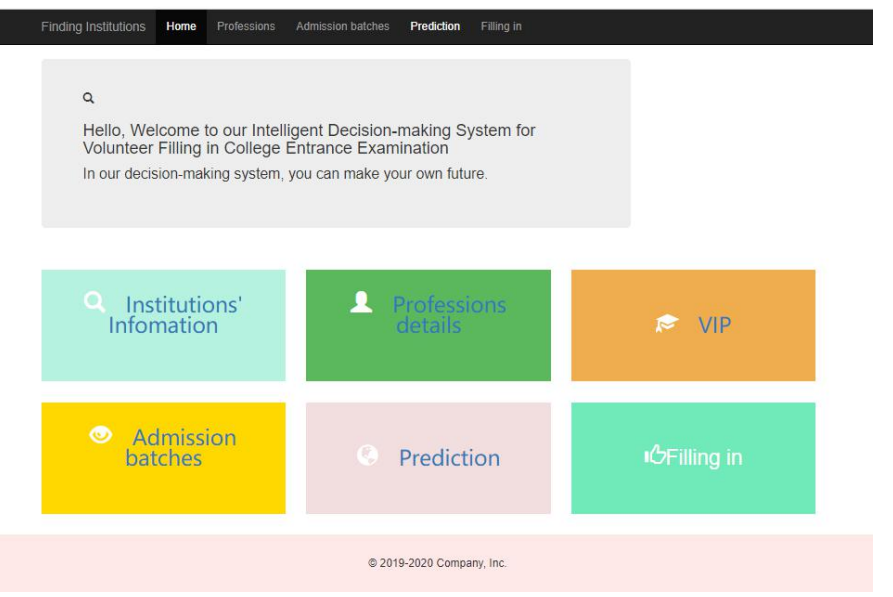

Fig. 1. Home Page



Fig. 2. Finding Institutions page

\section{A. Searching for College Information}

Through searching for interested universities, this paper introduces the relevant enrollment brochures and school characteristics. In order to let the students of Senior Three understand the detailed information and professional characteristics of the college.

\section{B. Professional Details}

By classifying candidates according to their types, such as only looking at science and technology or only looking at the major of literature and history, we have a good idea of the specialty under our major. Have a preliminary estimate of the names you are interested in, and deepen your understanding of the profession through online or consulting teachers.

\section{Offer Lines}

Choosing the area where the candidates are located, and check the scoring line control range in recent years. So as to have control over their overall performance, and constantly improve their knowledge level.

\section{Prediction of Colleges}

College prediction is as mentioned above, the specific operation steps are no longer described, according to the order of the institutions and the screening conditions of candidates, the final voluntary program is obtained, and an intelligent decision-making program of voluntary application will be given.

\section{E. Voluntary filling in}

In this module, the goal of voluntary prediction can be achieved through the combination of background database and machine learning algorithm. We will also continue to strengthen the learning of professional knowledge, and continue to strengthen the algorithm structure.

\section{F. VIP services}

In this module, we can see the courses and necessary skills of the corresponding majors. We can learn by ourselves in our spare time. In this module, we can see the direction of future employment, so that candidates have more room for development.

\section{RESEARCH AND ANALYSIS ON THE IMPACT OF INTELLIGENT DECISION-MAKING SYSTEM FOR COLLEGE ENTRANCE EXAMINATION FILLING ON HIGH SCHOOL STUDENTS}

\section{A. Analysis Based on Students}

Senior three students spent most of their time studying in their school. They do not know the history of the school they want to apply for, the comprehensive ranking of the school they want to apply for, the major they like to study, and the meaning of these obscure and difficult professional names. Therefore, the voluntary application after the college entrance examination has become a big problem.

In the face of voluntary filling in, some will deliberately seek the help of some voluntary filling in institutions, but the effect is minimal, spent a lot of money in vain. Senior three students have secretly vowed to test their ideal level; after all, they are still "ordinary students" and can't compare with the few "learning hegemony" in the class. How can they get into an ideal school in the thousands of troops crossing a thin wooden bridge? It is precisely because ordinary people need to redouble their efforts, so we need to seek intelligent decision-making of voluntary application, so that we can't be wrong because of their own ordinary university they do not like, if we really go to a completely unsuitable professional or college, so even postgraduate entrance examination is difficult to crossexamination. The fairest and most important chance to change our destiny is in front of us. How can we not fight? Examination mentality is also very important part, some students see that the students around them can learn much better than themselves without much effort; see that the students who are better than themselves can go to questions while studying by themselves, and they can't ask anything, they are also very anxious; see that the students bought a lot of exercise books and worked tirelessly to do a lot, the exercise books they just bought have not written their names.....All these lead to the students' mind extremely bad. Every swearing-in meeting, I always feel that I have endless strength, but one week later, this passion will decay a lot, they belong to the kind of self-hard work, but the results are not up to date. The results are not ideal, so there will be a lack of self-confidence. By inputting the results of the simulated examination into the intelligent decision-making system of the college entrance examination, we can find out the gap between ourselves and 
the ideal college, overcome the negative emotions, try to work hard to improve efficiency and flexibility, and quickly improve our academic performance. It would be a great pity to delay your future and time because you do not know how to do it. Our team members used their spare time to investigate the needs of high school students, and set up several modules on the homepage in order to make the students after the college entrance examination no longer suffer from volunteer filling in.

\section{B. Analysis Based on Parents of Examinees}

Parents want their children to have a good future, so they look for counseling institutions everywhere to volunteer to fill in guidance, which is tantamount to asking for directions, spending a lot of money, and wasting a lot of time. As parents, they should know their children character very well. If their children study very well, they can fill in the report according to their own wishes. But if the children are just ordinary students, or rather more diligent students, they can't fill in the report according to their interests when filling in their volunteers. Instead, they should fill in the report according to the trend of social development and the plan of future career. As well as possible professional paths for further education are integrated as much as possible. Students' interests are also unstable and immature, so do not let their interests decide what they will major. Watching several TVB plays is like being a barrister. Watching several Japanese and Korean dramas is like being an angel in white and an investigative journalist. They do not know the difficulties and hardships of these professions at all. It seems that parents are democratic and open-minded enough. In fact, they let their children temporary imagination influence their children future 5-10 years or even longer. This is irresponsible.

With our intelligent decision-making system for college entrance examination, we can update the simulated test results in time. Parents can see their children learning situation at a glance. They can also generate visual polygraph according to several simulated test results, so that parents can visually see the changes of their performance, and make appropriate psychological counseling, so as to make preparations for rainy days, discover problems in time and solve them in time.

\section{Analysis Based on Stimulating Students Inner Interest and Potential}

On the one hand, our system can also stimulate students' interest in learning. When they know the fluctuation of their performance, they will know what to do next. They can also adjust according to the suggestions of our system, so that they can enter the ideal target college.

On the other hand, the intelligent decision-making system of college entrance examination voluntary filling in the view of large data is based on machine learning recommendation algorithm for reasonable prediction. Machine learning gives computer training set for training, and then makes the same algorithm for the test set to draw conclusions. Candidate friends will have different ideas. Do you have to recommend algorithms? Or is there a better, better algorithm to replace the system algorithm? If students have such ideas, our other goal is to stimulate students' interest in studying the system, so that they will pay more attention to the study of mathematics and the knowledge of big data, thus replacing our core algorithm, achieving real interest in active learning and research, and upgrading their professional knowledge to one. Highly, lay the foundation for future career development. Interest plays an important role in human practical activities. Interest can make people concentrate their attention and produce a happy and tense mental state, which will have a positive impact on human being understanding and activities, and is conducive to improving the quality and effect of work. Interest is the best teacher. Once students have interest, creativity and innovation will be infinite.

\section{Analysis on Training Career Orientation [2] and Enhancing Independent Innovation Ability}

College Entrance Examination is the first orientation of life and the basis of career planning after entering university. The right choice of filling in College Entrance Examination determines the sustainability of College Students' career development. However, the passivity and blindness of college entrance examination volunteer choice and the demand of College Students' individual career development form a sharp contradiction, which greatly restricts the scientific planning of college students' career. Therefore, ordinary high school should strengthen the guidance and education of students' career planning in senior high school. Colleges and universities should actively carry out double-degree education through the reform of enrollment in major disciplines, and promote the independent, free and diversified development of College students. Our college entrance examination voluntary filling-in intelligent decision-making system has laid a foundation for students' career orientation and self-learning Basics.

Cultivating students innovation and entrepreneurship ability is the need of building an innovative country to implement the strategy of "rejuvenating the country through science and education". Innovation is the soul of national progress and the inexhaustible motive force of national prosperity. The competition of comprehensive national strength in today world is ultimately the competition of scientific and technological strength and high-quality talents. A country with innovative ability and a large number of high-quality human resources will have great potential for the development of knowledge economy. Vigorously cultivating students' innovative ability will enable a large number of young people with innovative thinking to be transported to society and effectively safeguard the national innovation system. Establish and conform to Chinese development strategy of rejuvenating the country through science and education and build an innovative country. The education we received from childhood is to innovate. It is because of innovation that we have the Internet plus era and the era of big data $\mathrm{AI}[3]$. Only when Chinese "new four inventions" came into being, can we have the sharing of bicycles. We need to cultivate our innovative consciousness and stimulate the innovative interest of candidates. Starting with the innovation of our system, I understand that our system is not the most perfect one. So we will launch an initiative to let candidates innovate our backstage algorithms and backstage design technology. In addition, the "VIP service" on the homepage is also open to candidates, so that they can apply 
innovation to reality and cultivate it. Prepare for the application of innovative talents.

For myself, I have my own technological innovations, such as deeper development using Python Web Django framework [4].As shown in Fig. 3.

Welcome to our College Entrance Examination Volunteer Filling System, where you can customize your own future!

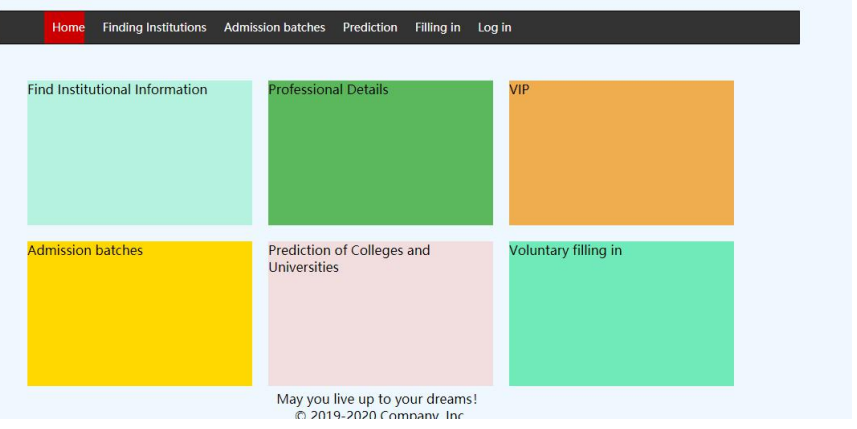

Fig. 3. Python web Django framework page design

\section{E. Analysis Based on Social and National Level}

In the era of big data, data is no longer static and obsolete. Any data forgotten in the server can be reused to discover its relevance to us, behavior and phenomena. Victor MayerSchoenberg, author of The Age of Big Data, said that the real value of big data is like an iceberg floating in the ocean. At first glance, you can only see the tip of the iceberg, most of which are hidden beneath the surface. Thanks to the progress of science and technology, today we can see the vast majority under the iceberg.

Today's era has entered the "Internet + big data era". Nowadays, China is in urgent need of talents with big data and artificial intelligence algorithms. If our college entrance examination makes an intelligent decision system through such an interest oriented guidance, if students should learn big data to learn other students who are not suitable for their majors, for these students that will be a national loss, and one of our goals is to reduce this loss and select professionals for the country so that they can make their own contributions. Of course, it is not just big data talents. As long as students in other fields are suitable for this field, we should guide them in the right direction and make our own contribution to the country's two hundred-year goal and to the development of China into a powerful socialist country.
As Chairman $\mathrm{Xi}$ has stated, great dreams come from the soil of reality. After suffering and brilliance, the Chinese nation always has the feeling of "home, country and world"[5]. The realization of national prosperity and people' prosperity has always been the dream of our nation and of every Chinese. In the history of the great rejuvenation of the Chinese nation, everyone is the witness, pioneer and builder of the times.

\section{CONCLUSION}

We have the experience of college entrance examination. We want to use our professional knowledge to make the senior three students no longer worry. We want them to understand what they are studying in various fields, or what specialty they are really suit for, so that they can guide them out in time when they encounter thinking bottlenecks in preparing for the exam, and tailor-made voluntary filling-in plan for the candidates that belongs to their own. Prepare for the country to select talents with high quality professional knowledge. We have developed an intelligent decision-making system for college entrance examination filling, which can really solve the problems for senior three students. By satisfying the internal database structure of ACID [6] characteristics, we can reduce the waiting time of candidates. The system has passed the application of small-scale testing and achieved good results. We will continue to summarize and improve the system, strengthen the optimization of internal algorithm of machine learning, and make the prediction rate reach a higher level.

\section{REFERENCES}

[1] http://www.chyxx.com/industry/201806/648845.html

[2] Yongxiang Zhang. Contradictions and Conflicts between College Students' Career Planning and College Entrance Examination Voluntary Choice and Their Coping Strategies [J]. Educational Theory and Practice, 2010, 30 (12): 43-45. (In Chinese)

[3] Bingyan Lu. Discussion on Applied Undergraduate Accounting Education in the Internet Big Data Era [J]. Science, Technology and Economy Guide, 2019, 27 (11): 145-146. (In Chinese)

[4] Philipp Chapkovski, Essi Kujansuu. Real-time interactions in oTree using Django Channels: Auctions and real effort tasks [J]. Journal of Behavioral and Experimental Finance, 2019, 23.

[5] Jinfeng Liu, the Party School of the Huangnan State Party Committee of the Communist Party of China, [N]. Huangnan Daily, 2019-06-28 (005). (In Chinese)

[6] Luciana Mateus Gonçalves, Jean Franciesco Vettorazzi, Emerielle Cristine Vanzela, Mariana Sarto Figueiredo, Thiago Martins Batista, Claudio Cesar Zoppi, Antonio Carlos Boschero, Everardo Magalhães Carneiro. Amino acid restriction increases $\beta$ - cell death under challenging conditions[J]. Journal of Cellular Physiology, 2019, 234(10). 